DOI: 10.20472/IAC.2018.039.019

\title{
LADO JIBUTI
}

Iv.Javakhishvili Tbilisi State University, Georgia

AMIRAN BIBILASHVILI

Iv.Javakhishvili Tbilisi State University, Georgia

\section{LOW-TEMPERATURE TECHNOLOGY OF RECEIVING HF AND Y OXIDES}

\begin{abstract}
:
In this work is given low-temperature plasma anodizing and magnetron sputtering technologies of receiving $\mathrm{Hf}$ and $\mathrm{Y}$ metals oxides, metal-insulator-semiconductor structure based on received oxides and research of oxides electro-physical parameters. Traditional technology of receiving oxide layers is carried out at a high temperature (1300K). High-temperature technological processes result in diffusion of unwanted impurities, increased surface roughness, worsened adhesion and uncontrolled growth of oxide films take place. In addition to the selection of oxides, it is important to decrease their formation temperature. Low temperature $(600 \mathrm{~K})$ technologies are plasma anodizing and magnetron sputtering technologies, stimulation of which is carried out with ultraviolet (UV) light irradiation directly during formation process of oxide layers. Using abovementioned technology formation temperature of oxide layers decreases and formation rate increases. As a result high quality oxides are received. As a base materials where used p-type Si with specific resistance of 10 Ohm $\times \mathrm{cm},(100)$ surface orientation and sapphire wafers with (0001) surface orientation, thickness $400 \mu \mathrm{m}$.

Using C-V method was measured inversion voltage, charge in oxide, dielectric constants and density of energy states in the oxide-semiconductor interface. Using current-voltage characteristic was measured leakage current and $\mathrm{x}$-ray analysis was done.

Measurement results showed that received oxides can be used as active layers in memristor.
\end{abstract}

\section{Keywords:}

Oxides, plasma anodizing, magnetron sputtering

JEL Classification: L63 